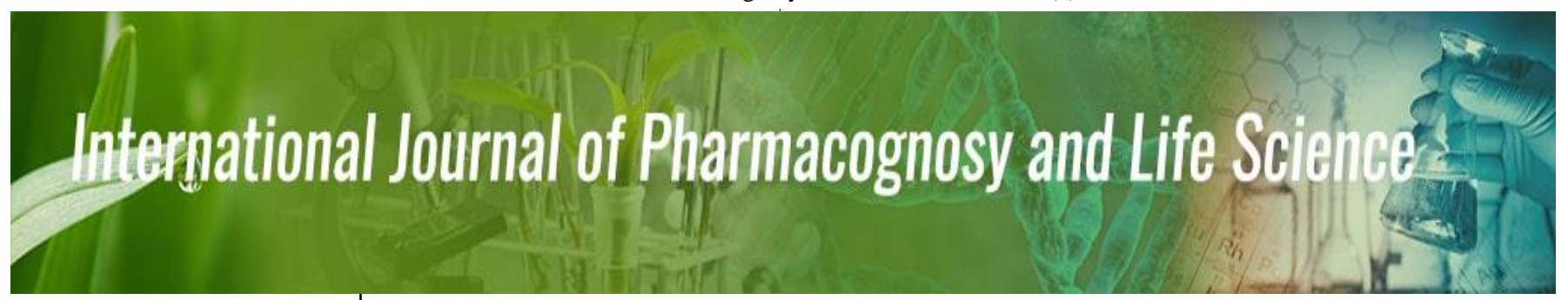

E-ISSN: 2707-2835

P-ISSN: 2707-2827

www.pharmacognosyjournal.com IJPLS 2021; 2(1): 01-10

Received: 02-11-2020

Accepted: 11-12-2020

Fatema Shorna

Department of Pharmacy,

BRAC University, Mohakhali,

Dhaka, Bangladesh

Shifat Sehrin Khan Upoma Department of Pharmacy, BRAC University, Mohakhali, Dhaka, Bangladesh

Timothy Singh

Department of Pharmacy,

BRAC University, Mohakhali,

Dhaka, Bangladesh

Pritesh Ranjan Dash

Department of Pharmacy,

Jahangirnagar University,

Savar, Dhaka, Bangladesh

Corresponding Author:

Pritesh Ranjan Dash

Department of Pharmacy,

Jahangirnagar University,

Savar, Dhaka, Bangladesh

\section{Covid - 19 perception conforming its emergence, detection, treatment options and future prospects: A review}

\author{
Fatema Shorna, Shifat Sehrin Khan Upoma, Timothy Singh and Pritesh \\ Ranjan Dash
}

DOI: $\underline{\text { https://doi.org/10.33545/27072827.2021.v2.i1a.21 }}$

\begin{abstract}
The sudden and unexpected outbreak of SARS-Covid-2 also known as Severe Acute Respiratory Syndrome- Corona virus disease- 2 has nearly killed $2.86 \mathrm{M}$ people worldwide and approximately affected 132M lives, thus for humans the situation has become catastrophic. The situation now has become more serious and severe considering the SARS-COV spread in 2003 from camels. A cure or a vaccine still look distant but scientists are working to better understand this virus. Four new studies about the coronavirus have come to light. Thailand has reported the first case of covid-19 transmission from a dead patient to a health worker. The medical examiner died after catching the infection from a dead body. This raises the concern over the risk faced by both working in morgues and funeral rooms. It is still not known how long the virus survives in a dead body. Heat does not kill or deactivate the corona virus. A Chinese study has found that the direction of air conditioning is a key factor for droplet transmission. Governments from many parts of the world are extending restrictions. How long will this last? Turns out one-time lockdown might not be enough to clamp down on the coronavirus. In fact, the scientists said that the Harvard University say that repeated periods of social distancing might be required till 2022. In comparison to all the articles and journals published on this emerging topic, our journal focuses on the history of COVID-19, its pathogenesis, its available treatment regimens, the different ways the virus was found to spread and its future prospects. We have summarized the findings in this paper. The main objective of our paper was to portray all the updated information on this emerging topic to inform and aware people of the future which is yet to come because of this sudden pandemic.
\end{abstract}

Keywords: Coronavirus, transmission, pneumonia, quarantine, isolation, pathogenesis

\section{Introduction}

27 cases of pneumonia with unfamiliar etiology were recognized in Wuhan City, Hubei province of China, on 31st December 2019, and on $7^{\text {th }}$ January 2020, the Chinese Centre for Disease Control and Prevention (CCDC) identified the causative agent from throat swabs taken from the patients. It is believed to have been transmitted Zoonotically, in a wet market in Wuhan where hunted animal meats were put up for sale. Afterwards the microorganism was named Severe Acute Respiratory Syndrome Coronavirus 2 (SARS-CoV-2) ${ }^{[1]}$ and the disease was named COVID-19 by the World Health Organization [2]. Till April approximately $132 \mathrm{M}$ cases of COVID-19 and $2.86 \mathrm{M}$ deaths have been registered, with children being rarely affected with no casualties ${ }^{[3]}$. The majority of SARS-CoV-2 infected patients have developed mild symptoms such as dry cough, sore throat, and fever and have naturally recovered, but some fatal complications were also reported such as pulmonary oedema, severe pneumonia, organ failure, septic shock, and Acute Respiratory Distress Syndrome (ARDS) ${ }^{[4]}$. 54.3 percent of those ill are men with average age of 56 years andolder patients needed intensive care support who had multiple conditions like cardiovascular, digestive, cerebrovascular, endocrine, and respiratory disease. Those in intensive care also reported dyspnoea, abdominal pain, dizziness, and anorexia ${ }^{[5]}$.

Coronaviruses $(\mathrm{CoV})$ belongs to the family of viruses called Coronaviridae and its subfamily Coronavirinae has three genera, alphacoronavirus, betacoronavirus, and gammacoronavirus. [6]. These viruses are zoonotic, meaning they can spread between animals and humans. A couple of coronaviruses were previously identified: MERS-CoV, which causes Middle East respiratory syndrome and was transmitted from dromedary camels to humans, and SARS- 
$\mathrm{CoV}$, which causes severe acute respiratory syndrome and was transmitted from civet cats to humans ${ }^{[7,8]}$.

\subsection{History}

Coronaviruses range from $60 \mathrm{~nm}$ to $140 \mathrm{~nm}$ in diameter with enveloped positive sense RNA and has projections on its coat. This gives it a crown like appearance under the electron microscope; which led to the name coronavirus ${ }^{[9]}$. HKU1, NL63, 229E and OC43 are corona viruses which circulate in humans, causing mild respiratory disease, however, two events in the past two decades of animal betacorona viruses' crossover to humans caused serious diseases. In 2002- 2003 in Guangdong province of China, a new coronavirus of the $\beta$ genera originating from bats crossed over to humans through palm civet cats, which acted as the intermediary host. This virus was called severe acute respiratory syndrome coronavirus (SARS-CoV) affected 8422 people and caused 916 deaths (mortality rate $11 \%$ ). This was mostly in China and Hong Kong ${ }^{[10]}$. Almost a decade later in 2012, the Middle East respiratory syndrome coronavirus (MERS-CoV) was found in Saudi Arabia, with dromedary camels as the intermediate host and originating from bats as well. This affected 2494 people and caused 858 deaths, with a much higher fatality rate of $34 \%$ [11].

\subsection{Ways of transmission}

Only a few studies were able to characterize the pathophysiological characteristics of COVID-19 and it's spreading process and this information is developed from comparable coronaviruses which spread from human-tohuman through respiratory fomites ${ }^{[12]}$. We previously knew that respiratory viruses are transmissible when a patient is showing symptoms, but recent studies indicate that transmission may happen when the patient is not showing any symptoms. This is called the incubation period and for COVID-19, it is estimated to be between 2 and 10 days, median 5 days ${ }^{[13]}$. The major carriers for coronavirus are respiratory droplets which can stay in the nose and mouth or move into the lungs when someone breathes in. Moreover, touching either an infected surface or even an object can lead to human-to-human transmission, but the transmission rates vary from person to person, location and interaction with involvement in infection control. However, the awareness of how the virus spreads has led to airborne safety measures with high-risk procedures that are being followed in many countries ${ }^{[14,15]}$.

\subsection{Pathogenesis}

The virus is transferred via large droplets produced by a symptomatic patient's coughing and sneezing, but can also happen from an asymptomatic person who has no symptoms ${ }^{[13]}$. Studies have indicated a much greater viral load in the nasal cavity when linked to the throat, but shows no variation in viral burden between symptomatic and asymptomatic people ${ }^{[16]}$. Moreover, the patients can be contagious even on clinical recovery. These infected droplets can scatter 1-2 meters and can remain alive for days on deposited surfaces if the conditions are optimum, but disinfectants like sodium hypochlorite, hydrogen peroxide can destroy the virus in less than a minute ${ }^{[17]}$. The infection spreads by inhalation of the droplets or touching surfaces tainted by them and then touching the nose, mouth and eyes. The virus is also present in the stool and this has led to the theory that contamination of the water supply and successive transmission via aerosolization or feco-oral route can occur ${ }^{[18]}$. So far there were no cases of transplacental transmission during pregnancy but neonatal disease due to post natal transmission is possible ${ }^{[19]}$.

Studies have identified that the virus enters the respiratory mucosa by attaching to the angiotensin receptor 2 (ACE2). The basic case reproduction rate (BCR) is estimated to range from 2 to 6.47 in various modelling studies ${ }^{[20]}$ and in comparison, the BR of SARS was 2 and 1.3 for pandemic flu H1N1 $2009^{[3]}$. Both vivo and in-vitro experiments have shown that coronaviruses are tremendously precise and mature in most of the airway epithelial cells and results in higher nasal discharge along with local oedema caused by harm to the cell, which further accelerates the production of inflammatory mediators. This causes sneezing, difficulty breathing, and elevate mucosal temperature and mainly affect the lower respiratory tract. The virus also affects the renal cells, liver cells, intestinal lymphocytes and $\mathrm{T}$ lymphocytes thus causing $\mathrm{T}$-cell apoptosis and subsequently resulting in the collapse of the immune system ${ }^{[21,22]}$.

\section{Symptoms: Visible and clinical}

The clinical characteristics of COVID-19 are wide-ranging, starting from the asymptomatic state which can lead up to acute respiratory distress syndrome, as well as multi organ dysfunction. Fever, cough, sore throat, headache, fatigue, headache, myalgia and breathlessness are the most seen clinical features but conjunctivitis has also been described in rare occasions. This makes the virus impossible to differentiate from other respiratory infections. In few patients, the disease can advance to pneumonia, respiratory failure and death in one week. This progression is related with excessive rise in inflammatory cytokines like IL2, IL7, IL10, GCSF, IP10, MCP1, MIP1A, and TNF $\alpha{ }^{[4]}$. The average time from onset of symptoms to dyspnea was 5 days, hospitalization 7 days and acute respiratory distress syndrome (ARDS) 8 days and $25-30 \%$ of affected patients needed intensive care. Some of the complications observed were acute lung injury, acute kidney injury and ARDS. It took 2 to 3 weeks for the recovery process to begin and the mean duration of hospital stay was 10 days. Adverse consequences led to death for aged patients and those who were suffering from other co-morbidities $(50-75 \%$ of fatal cases). Fatality rate for the adult patients taken to the hospital ranged from 4 to $11 \%$ and in general the fatality rate is estimated to range between 2 and $3 \%{ }^{[3]}$. Intriguingly, patients outside of Hubei province showed milder symptoms from those in Wuhan ${ }^{[23]}$ and the severity and case fatality rate in patients outside China were also less ${ }^{[18]}$. The reason could be due to selection bias wherein Wuhan reported only the severe cases or because of the Asian population's predisposition to the virus as they had greater expression of ACE2 receptors on the respiratory mucosa ${ }^{[20]}$.

Neonates, infants and children have shown significantly milder symptoms than adults. 34 children were admitted to a hospital in Shenzhen, China between January $19^{\text {th }}$ and February $7^{\text {th }}$ and there were 14 males and 20 females with an average age was 8 y 11 months. 28 children's infections were associated to a family member and 26 children had history of travel or lived in Hubei province. All the patients were either asymptomatic $(9 \%)$ or had mild symptoms, with fever $(50 \%)$ and cough $(38 \%)$ being the most common. All the patients recuperated with symptomatic therapy and no 
deaths. Only one case of serious pneumonia and multi organ dysfunction was observed in a child ${ }^{[24]}$. Similarly the neonates showed mild symptoms as well ${ }^{[25]}$.

\section{Four new studies about the coronavirus come to light 3.1 Corpse to human transmission possible}

Covid-19 a disease originated from the heart of China in Wuhan district is a debilitating treat on the face of earth ${ }^{[26]}$. With the rapid progression of its spread around the globe led to its declaration as a pandemic ${ }^{[27]}$. It possesses a great threat in the existence of humanity and is an increasing challenge for the medical community to thwart its progression which might culminate in medical personals being affected by this disease (main). Thailand is one of the multiple countries that were hit by this virus. Off the 272 recorded patients in Thailand according to reports from March 20, 2020, one of them is medical personnel who worked as a forensic practitioner in Bangkok ${ }^{[28]}$. At the moment the cases of Covid-19 of medical practitioner is limited to two but community exposure leading to their development of corona can be debated as most of the cases of Thailand are imported and reports of community transmission is low due to lockdown and severity of restriction. However, they were exposed to corpse and medical samples. Although no prevailing data has shown any inklings leading to the development of the disease but precautionary measures that are followed prior to operation for disinfection can go a long way along with wearing protective kits, goggles, gloves, suits, mask and caps ${ }^{[29]}$.

\subsection{Air-conditioning flow impacts spread}

A Chinese paper was published elucidating the prospect the air-conditioning as a potential factor for the spread of Covid-19. Here 10 members from three distinctive families became covid-19 positive upon going off to a restaurant for lunch in Guangzhou, China. All the family members were seated in respective tables which was separated by $1 \mathrm{~m}$. After the lunch it was found that total 9 members from the three families came covid-19 positive upon testing. It was suggested that 3 of the other members of the first family became covid-19 positive due the exposure with the one of the members of the first family. Three members of the second and two members of the third family also came covid-19 positive which was also attributed due to the community transmission through one person of the first family. As the building was 5 stored with no windows and the only source of ventilation was through the air conditioners outlets and inlets thus it was assumed that the virus might spread through air. Upon testing through PCR, the smears from the total six (three inlet and three outlets) of the air conditioner it was seen that they came covid-19 negative ${ }^{[30]}$. The above scenario points out that the plausible route of transmission might be by droplet transmission [31]. Thus it can be said that air droplets with the air conditioner outlets and inlets might propel the virus and act as carrier to other members from the respective families. Larger Air droplets $(>5 \mu \mathrm{m})$ remains shortly in air and can travel a distance roughly less than $1 \mathrm{~m}^{[32,33]}$. However, all the family members of the respective families were seated at distance of $1 \mathrm{~m}$. But contemporary studies have shown that aerosolized small droplets $(<5 \mu \mathrm{m})$ can traverse a distance more than $1 \mathrm{~m}^{[34]}$. And many studies have been carried out for both MERS-COV and SARS-COV-1 in this regard ${ }^{[35,36]}$ which could strengthen the fact that air droplets through the air-conditioned ventilation system might be the carrier. However, no other members of the hotel were affected this might be attributed to the low density of the aerosol and the greater distance it needed to travel to cause transmission.

\subsection{Heat will not kill the virus}

In light to contemporary events we can see that the world has been star struck with a new form of Severe Respiratory Syndrome classified also as Pandemic known as Covid-19 caused by SARS COV-2 ${ }^{[37]}$. Tedious efforts are done to subside the increasing number of the affected amidst the scientific personals ${ }^{[38-40]}$. Even though an introduction of laboratory guidelines has been implemented by WHO but still the number of people affected are still on the rise amidst laboratory workers [41,42]. Nucleic Acid extraction through RT-qPCR test and buffers is the acceptable method for the detection of SARS-COV-2. Albeit non-infectious samples are tested through Automated NA extraction which requires the prior inactivation of sample under convenient biosafety conditions. Even though the lysis buffers as an inactivating agent for multiple pathogens were done but discrepant results from dissimilar protocols infers difference in conclusion [43-45]. Many laboratories have aligned themselves in accordance with CDC's approved method by treating the viral sample with Triton X-100 for an hour at 60 degrees, on the contrary many encompassing the treatment of MERS and SARS-COV have failed to show any significant results even though it showed promising results against Ebola [46, 47]. In due course of time serological studies will be implemented as a medium of diagnosis and seroprevalence studies will be done aiming to measure the extent of the viral spread amidst the mass people ${ }^{[48]}$. All samples should be inactivated prior to serological studies ${ }^{[49]}$. Here we have analyzed 6 protocols namely: Lysis buffer, Cell line, SARS-COV-2 titration, Inactivation assay with Lysis buffer, Heat Inactivation Assay and Integrity of SARS-COV-2 virus after heat inactivation.

Three lysis buffers were produced in Germany namely ATL (25-50\% Guanidinium Thiocyanate [GITC] and 1-10\% sodium dodecyl sulfate [SDS]), VXL (25-50\% GITC, 2.5$10 \%$ Triton-X-100) and AVL (50-70\% GITC). Both VXL and ATL were successful in the inactivation of SARS-COV2 with loads as much as $10^{6} \mathrm{TCID}_{50} / \mathrm{ml}$. On the contrary a partial inactivation up to the extent of $50 \%-75 \%$ was seen when AVL buffer (GITC 50\%-70\%) either alone or in combination with absolute ethanol or $1 \%$ Triton X-100 and no difference in results were found between clean and dirty conditions ${ }^{[45]}$.

In case of heat inactivation, only a total inactivation $(>6$ $\log _{10}$ ) of the virus seen when the protocol where the virus was heated at $92^{\circ} \mathrm{C}-15$ minutes was followed and on the contrary the other two protocols only gave a drop of inactivity $\left(5 \quad \log _{10}\right)$ reduction but with $10 \quad \mathrm{TCID}_{50} / \mathrm{ml}$ infectiveness equal or lower than that. The resulted showed no difference between clean or dirty situation and maintained coherence with previously done studies of MERS-COV and SARS-COV [46, 47].

In the instance of Integrity of SARS-COV-2 virus after heat inactivation, upon analysis of CT values showed no detectable significant drop in the number of RNA copies when heated at $56^{\circ} \mathrm{C}-30 \mathrm{mins}$ and $60^{\circ}-60 \mathrm{~min}$. However, a sharp drop was seen at $92^{\circ} \mathrm{C}-15 \mathrm{~min}{ }^{[50]}$.

Despite of previous repetitive emergence of SARS-COV and MERS-COV few studies and protocols were directed 
with view to mitigate the risk of exposure for laboratory and medical personals ${ }^{[51]}$. In case of viral inactivation, the competence of AVL was debated for quite a time but no substantial data was seen for ATL and VXL ${ }^{[43-45]}$. Studies on SARS-COV-2 was done using ATL, AVL and VXL both with and without the alliance with Triton-X100 in accordance with the French and European procedure (16) which was formerly followed for Ebola and Foot or mouth disease viruses ${ }^{[43,45,52,53]}$. The results align with the data of Ebola ${ }^{[45]}$ and strongly suggest the pertains the preference of ATL and VXL over AVL ${ }^{[54]}$.

As covid-19 patients tend to display a decreased load of viremia even at the acute stage of the disease ${ }^{[51]}$ thus for SARS-COV-2 inactivation the $56^{\circ} \mathrm{C}-30 \mathrm{mins}$ and $60^{\circ}-60 \mathrm{~min}$ protocol are to be followed prior to serological studies ${ }^{[55]}$. On the contrary, samples with higher incidence of viral loads ${ }^{[48]}$ requires the use of $92^{\circ} \mathrm{C}-15$ min which culminates in the total inactivation of the virus in contrast with the other two protocols ${ }^{[50]}$.

\subsection{Social distancing required till 2022}

The catastrophe of Covid-19 has caused significant casualties all around the globe. With no imminent treatment at hand we are forced to reside with contact tracing, social distancing and quarantine. However, the subsequent transmission dynamic of SARS-CoV-2 and the initial pandemic response would dictate the intensity, urgency and direction of this measure. To alleviate the chances of any further plausible resurgence begets extensive intermittent phases of social distancing ${ }^{[56]}$. Chances are that SARSCoV-2 could follow the path of its predecessor Influenza causing seasonal reappearance followed by the initial global infection ${ }^{[57]}$. Factors such as duration of immunity, cross immunity and the degree of transmission attributed to seasonality will greatly affect the pre and post pandemic dynamics of Sar-CoV-2 and also elucidate the intensity of the virus and the control measures to be taken into account ${ }^{\text {[58] }}$. A closer relative of Covid-19 being HCoV-OC43 and $\mathrm{HCoV}$-HKUI exhibit asymptomatic or modest amounts of upper respiratory tract infections and suggest the plausibility of winter outbreaks ${ }^{[59,60]}$. Although the immunity of $\mathrm{HCoV}$ OC43 and HCoV-HKUI is said to last between a span of one year, SARS-CoV-1 is attributed to provide longer lasting immunity ${ }^{[61]}$. The mortality rate of Covid-19 seems to be less apprehensive the its predecessors lying within a range of $0.6 \%-3.65 \%$ but its elevated infectious rate made it impregnable to control it ${ }^{[62,63]}$. Case based intervention, extensive testing, social distancing has been the steppingstone in precluding the spread of the disease with the aspiration to prevent the overwhelming of the health system, contriving time for vaccine along with flattening the curve ${ }^{[64]}$. Whether the critical care competencies are exceeded are not are said to be a key metric to social distancing intervention which provides inklings to expeditious construction of infrastructures, repurposing and dissemination of ventilators ${ }^{[65-68]}$. Findings were integrated in a mathematical model to ascertain the scenarios that are like to happen in the pre and post pandemic ${ }^{[69]}$.

Duration of Immunity, Cross Immunity, transmissibility and seasonal variation of $\mathrm{HCoV}-\mathrm{OC} 43$ and $\mathrm{HCoV}$-HKUI were assessed to ascertain the historical beta corona virus incidence in US ${ }^{[70]}$. In order to do this, the weekly population weight proportion of physician visit due to Influenza like illness is multiplied with weekly percentage of positive laboratory test of $\mathrm{HCoV}-\mathrm{OC} 43$ and $\mathrm{HCoV}-\mathrm{HKUI}$ [59]. The analysis was limited to "in season" with peaks reaching pinnacle between October and November and trough between in February and May (main). To assess the effect of seasonal forcing versus contribution of immunity in the overall transmission dynamics of beta corona virus regression model was adapted ${ }^{[71]}$. As anticipated a negative correlation coexisted with the transmissibility of strains and depletion of susceptible for each strain. A substantial proof of cross-immunity was assessed based on the negative correlation that is elucidated between the depletion of susceptible strains and reproduction of other beta corona viruses. Seasonal forcing seems to be dictating the pace in the rise and fall in the transmissibility of the virus ${ }^{[61]}$.

A third beta corona virus was incorporated in the assessing the dynamic transmission model to illustrate SARS-CoV-2 and a latent period of 4.6 days followed by an infectious period of 5 days was considered based on the best fit values in comparison with other beta corona virus [72-75]. For determining the sets of parameters values we assessed computed the annual SARS-CoV-2 infection and the peak annual SARS-CoV-2 prevalence throughout 2025 [69]. Model simulations gave insights to following key groundbreaking points:

a. Proliferation of SARS-CoV-2 can occur over the year at any time. Throughout all models SARS-CoV-2 has shown significant outbreak notwithstanding the established time frame with winter/spring portraying smaller peaks to giving elevated peaks in autumn/winter ${ }^{[69]}$.

b. An analogous nature of long-term circulation alongside other beta corona virus and influenza was seen in SARS-CoV-2 with plausible sporadic, biennial or annual patterns over the span of five years with short term immunity favoring annual outbreaks and longterm immunity portraying biennial outbreaks ${ }^{[69]}$.

c. Seasonal variation greatly affects the pandemic peaks with portraying smaller peaks during the commencing of the initial phase of the pandemic followed by a leap in the peak with recurrent outbreak in winter ${ }^{[69]}$. A stark difference might be seen between the SARS-CoV2 transmissions in respective geographical location which is attributed to the seasonal variation which was also evident in case of influenza ${ }^{[76]}$. A substantial number of susceptible individuals are accumulated in low transmission phases due to strong seasonal forcing which sequels in elevated peaks in post pandemic period $^{[69]}$.

d. The development of long-term immunity to SARSCoV-2 and cross immunity against other beta corona virus might sequel in perpetual loss of the virus or its disappearance for a long period of time ${ }^{[69]}$.

e. If the instance of cross immunity exist between other beta corona virus against SARS-CoV-2 could cause a temporary absence of SARS-CoV-2 with a likeness to resurge in a few years ${ }^{[69]}$.

With no pharmaceutical treatment at our disposal we resort back to the non-pharmaceutical intervention as our only array of hope to hinder the progress of the disease transmission. Social distancing is another approach adopted by the world to fight this global pandemic. To assess the infection resulting to hospitalization (95.6\%), moderate/mild/asymptomatic infections, infections leading 
to hospitalization with no imminent critical care $(3.08 \%)$ and infections requiring critical care (1.32\%) a SEIRS transmission model was adopted ${ }^{[72]}$. AS assumption of the worst case scenario that might occur the instance of no cross immunity was considered for both $\mathrm{HCoV}-\mathrm{OC} 43$ and $\mathrm{HCoV}$ HKU1 against SARS-CoV-2 with estimates determined from previous studies suggesting a 5 days infection period and 4.6 days latency period ${ }^{[72]}$. Whereas the day for hospital stays based on the severity of infection and hospital stay were ascertained as follows: non-critical requiring hospital stay, not requiring critical care and requiring critical care are said to be 8, 6 and 10 days respectively ${ }^{[72]}$. A regression model where wintertime peaks were considered between 2.0 and $2.6 \mathrm{R}_{\mathrm{o}}$ and summertime variability was allowed between $60 \%$ signifying relatively strong seasonality and $100 \%$ portraying no seasonality as a mere demonstration of the inferred seasonal forcing for $\mathrm{HCoV}-\mathrm{HKU} 1$ and $\mathrm{HCoV}$ OC43 ${ }^{[69]}$.

As a reference point the USA's 0.89 free critical care beds per 10, 000 was considered. The simulations and the trajectory of the pandemic was done keeping in mind the established timeline of the epidemic being 11 March 2020 and the social distancing was incorporated and simulated by a reduction in $\mathrm{R}_{\mathrm{o}}$ between $0 \%$ to $60 \%$. For one-time social distancing $\mathrm{R}_{\mathrm{o}}$ was reduced by $60 \%$ for a short period of time and for intermittent social distancing interventions, distancing was turned on when the infection number crossed the threshold and stopped when it fell below the threshold. An extra compartment was implemented in the model with a view to elucidate the infectious period, latent period and hospital period so that they were gamma distributed rather than exponentially distributed. And lastly the repercussion of doubling of critical care capacity was also assessed ${ }^{[69]}$. When one-time social distancing was implemented and subjected both no and with seasonal forcing in both scenarios resulted in the resurgence of the infection. Although the peak of curve fell when social distancing was implemented with no seasonal forcing but resurgence was seen even long term social distancing failed to correlate with the epidemic peak where even after $60 \%$ in $\mathrm{R}_{\mathrm{o}}$ still depicted a meteoric rise in the curve when the restrictions were lifted and was almost of the same size of the uncontrollable pandemic ${ }^{[77]}$. And the post intervention peak following seasonal forcing could even surpass the size of the uncontrollable epidemic peak in terms of patients affected and prevalence of the peak. And both the interventions failed to keep the prevalence of critical case below the anticipated level ${ }^{[69]}$.

On the contrary intermittent social distancing might pave the way to keep the critical case prevalence well below the expected level with an innate history of having a lag of 3 weeks amidst the peak critical demand and the start of social distancing thus upon transmission when seasonally forced sequels in less frequent social distancing with the $R_{o}$ remaining stagnant at its maximal wintertime value throughout the year. However, the degree of social distancing will elevate and decline in parallel terms with the epidemic. Gamma distribution of hospitalization, latent and infectious periods necessitates a lower level of social distancing and aggravating the critical care competency greatly bolsters the amassment of immunity which in turns paves the way to subside the duration of the epidemic and social distancing ${ }^{[69]}$.

Recurrent resurgence and winter outbreaks are likely to occur if the immunity to SARS-CoV-2 wanes in the same manner and the likeness to incidence through 2025 is hinges on the cross immunity exerted by the for HCoV-HKU1 and HCoV-OC43 and the duration of the immunity. Th basic reproduction number at the time of epidemic will dictate the severity of the intensity of the initial wave which if established in autumn when reproduction numbers are rising in countries that control epidemics through contract tracing and quarantine are likely to experience a steep curve if SARS-CoV-2 doesn't follow the same pattern in terms of transmissibility analogous to $\mathrm{HCoV}-\mathrm{HKU} 1$ and $\mathrm{HCoV}$ OC43. Intermittent social distancing might fend off the meteoric rise in the critical care necessity which necessitates extensive interventions and surveillance on the contrary one-time social distancing might exacerbate the load on critical care capacity by shifting the epidemic peak of SARS-CoV-2 in autumn. Measures like intervention, quarantine and vaccines and extensive contact tracing seems impractical in many cases on the contrary stringent intermittent social distancing and surveillance is the only array of hope to flatten the curve ${ }^{[78]}$. To impede this pandemic necessitates the urgency in the elevating the critical care capacities, surveillance and comprehending the duration of immunity of SARS-CoV-2 through serological studies [69]. Implementation of strong intermittent social distancing is essential in impeding and restricting the widespread of SARS-CoV-2 amidst the absence of other preventive measures and would circumvent in overwhelming the critical care competency ${ }^{[79]}$. It has been found that strong temporary social distancing sequels in the rise of large quantity of resurgence in accordance with the 1918 influenza pandemic data ${ }^{[80]}$.

There were multiple limitations in the study:

a. Only five season's corona virus data were taken into consideration ${ }^{[60]}$.

b. An assumption was made regarding the spine coefficient was made as it being constant across all seasons.

c. Across different beta coronavirus no difference was assumed amidst seasonal forcing, per-case force of infection, latent period and infectious period. However, the assumptions were well within the literature estimates.

d. Age structure differences in disease transmission was not parameterized due to unavailability of the data.

e. Did not take into consideration of the effect of school opening on disease transmission ${ }^{[81]}$.

f. The model fails to show its adeptness in determining the plausibility of extinction SARS-CoV-2 dude to being deterministic in nature.

g. Fails to account for the heterogeneous spatial transmission as it fails in its attempts to incorporate geographical structures.

Percent test positive was multiplied with percent ILI find the probable coronavirus incidence up to proportional constant ${ }^{[82]}$. The true estimate of the overall corona virus incidence cannot be done due to the lack of accurate data of corona virus infections ${ }^{[76]}$. Serial intervention studies were implemented in this method which was previously not followed extensively in case of other beta corona viruses. The findings are subjected to approximately $60 \%$ of the world population and much of it belonging to the temperate regions ${ }^{[83]}$. Serological studies play a pivotal role in being 
the determinant of the extent to which immunity wanes through this period and see if cross immunity exists between SARS-CoV-2, HCoV-HKU1 and HCoV-OC43 [84]. Thus it was anticipated the enhancement in the cross immunity might subject in the subsiding the intensity of SARS-CoV-2 $[85,86]$. Intermittent social distancing requires extensive surveillance and to bolster our interventions requires taking steps to circumvent the critical care capacities [62, 87, 88]. Countries achieving a commendable level in controlling the outbreak should take marauding steps in constraining future waves of the infections ${ }^{[89]}$. A vaccine would bring an array of hope and greatly subside the epidemic through rendering accelerated immunity and the prospect of herd immunity can further bolster the path to obtaining threshold immunity then described in this model ${ }^{[69]}$.

\section{Treatment regimens}

Generally, the known three options by which the strategies to stop any pandemic including COVID-19 are finding ways to control the infection source, to mitigate the route of transmission and also to protect the population who are more vulnerable and susceptible. Sadly, no vaccine, drug or any therapy has showed continuous or fair efficacy for patients diagnosed with Covid -19. Most of the treatments are still being assessed or are on trial for their potency in COVID-19 patients. Majority of the medicines were effective for other similar diseases and cases but their usage in case of COVID-19 patients still remains thoughtful and investigational ${ }^{[90]}$.

\subsection{Remdesivir}

Remdesivir was the first drug used in the potential treatment for SARS-CoV-2 in vitro as it was also effective against previous similar pandemics such as MERS and SARS in vitro As well as animal studies. A study of 53 severe Covid19 positive patients carried out on remdesivir portrayed that $68 \%$ of these severely ill patients showed improvement. However, few adverse effects were noted too which includes hypotension, increased liver enzymes, rash in skin, diarrhea and increase in creatinine level ${ }^{[91]}$.

\subsection{Favipirvir}

These drugs were very recently approved in China (15February-2020) for the treatment of Influenza virus. The drug also showed effectiveness in ongoing trials for SARSCOV-2, hence it was also used as a potential Covid- 19 drug. It works by inhibiting RNA polymerase and also has the potential to inhibit replication of alpha-, flavi-, filo-, noro-, arena- and many other RNA virus on the go ${ }^{[92]}$.

\subsection{Hydroxychloroquine/chloroquine}

These two drugs have shown potency in inhibiting the SARS-CoV-2 in vitro. Because of insufficient data on humans, clinical trials of Covid-19 are still suggested by FDA. However, due to the present crisis and emergency, FDA has given the permission to use hydroxychloroquine on particular cases. Reports showed that patients with HCQ intake showed faster recovery, improvement in radiological imaging of chest and lungs and also fewer chances in progressing to severe case. Unfortunately, most of the reports were done on basis of little population group or in some cases no placebo group hence a perfect and accurate meta-analysis is still not concluded ${ }^{[93]}$. Furthermore, alongside the clinical benefits of HCQ there are many side effects of the drug as well which includes retinopathy, cardio-myopathy and prolonged QT interval and therefore use of these drugs were restricted without seeking proper medical supervision.

\subsection{High-dose intravenous immunoglobulin (IVIg)}

IVIg is another therapy very similar to plasma therapy where the blood product contains polyclonal immunoglobulins which are extracted from healthy donors (recovered patients from Covid-19). IVIg is usually used for many other infectious, autoimmune, idiopathic and neuromuscular disorders ${ }^{\text {[94] }}$. Previous reports of IVIg during SARS and MERS showed the clinical benefits outweighed the side-effects and hence it is currently being accessed and used for patients suffering from Covid-19. Cao et al. conducted his research with 3 patients and found that this therapy improved the patients' health both radiologically and clinically and furthermore all the 3 patients survived and were discharged ${ }^{[95]}$.

\subsection{Convalescent plasma}

In this therapy, passive antibody is given to the newly infected patients and the antibodies are collected from patients cured from Covid-19 and has enough antibodies against the SARS-CoV-2 circulating in the blood. It has been found to be effective for the treatment of COVID19.This therapy is done by the usage of titers with high power for neutralizing immunoglobulin which contains blood plasma from previously recovered COVID-19 patients ${ }^{[96]}$. The main challenge in this therapy is to find a suitable donor along with high titers for neutralizing plasma activity. Despite the challenge and outcomes, this therapy has proven to be a potential remedy for severely ill patients in Covid -19 pandemic.

\subsection{IL-6 pathway inhibitors}

Drugs such as Sarilumab, Tocilizumab and Siltuximab have shown their potency in clinical use for majority of the inflammatory diseases and also many types of cancers as well. For instance, the drug named Tocilizumab was licensed for its effectiveness in case of cytokine release syndrome (CRS). Reports show that Covid-19 patients who are critically ill show symptoms of either mild or severe CRS which further leads to other conditions including

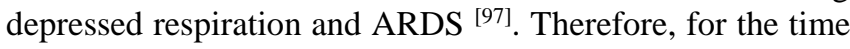
being China has given the authorization to use the drug, tocilizumab in COVID-19 patients who are also suffering from pneumonia. In addition to that, clinical trials are still ongoing for the safety use of tocilizumab and sarilumab in Covid-19 patients with severe pneumonia.

\subsection{Cell and biological therapy}

Mesenchymal stem cells have been accessed for their function of immunomodulation and significant and ideal studies have been carried out for immune mediated disease such as graft- versus - host disease and systemic lupus erythematosus. Researchers have accessed the immunomodulatory effect of MSCs in Covid-19 effected patients including pneumonia. They injected 7 patients around 1 million MSCs for each kilogram of the patients weight and portrayed an improvement in all the 7 clinical patients with no adverse reactions and effects ${ }^{[98]}$. Taking this observation in count, a future clinical trial is on progress to access the efficacy and potency of transplantation of 
ACE2-MSC in COVID-19 pneumonia patients.

\section{Conclusion}

The world is still on halt and unaware of what the future holds about this pandemic and also the people are not well prepared for the second wave of the pandemic as the researchers and scientists are still having a hard time to find a specific cure or a vaccine for the virus. The world is relying on the available treatment options which are till date not showing clinical benefits on everyone. And furthermore it is also being said that there won't be any specific medical options available in the general market for the public for around next 2 years. This pandemic has spread worldwide within the blink of eyes, previous findings have been proven wrong about the virus as it keeps on taking new forms because of mutations. Right now, each and every individual needs to step forward to help halt its spread by remaining indoors as much as possible and also self-quarantining the ones affected.

\section{Acknowledgement}

Authors are grateful to Jahangirnagar University, Department of Pharmacy, Savar, Dhaka, Bangladesh for providing necessary facility to carry out the study.

\section{Author's contribution}

The review was conducted under the supervision of Pritesh Ranjan Dash (PRD) who also designed the study. The abstract was written by Fatema Shorna (FS). The introduction, history, ways of transmission, pathogenesis and symptoms: visible and clinical were done by Shifat Khan (SK). The four studies regarding COVID-19 were detailed out by Timothy Singh (TS). FS also worked on the different treatment regimens available, conclusion and future precautions to be undertaken in this paper. All authors read and approved the final manuscript.

\section{Future precautions}

In recent years, the world has been warned and affected three times for similar outbreaks. Researches and scientists should focus more on the several aspects of diseases in human and also the different determinants in case of vaccine efficacy and safety.

\section{Consent for publication: Not applicable. 10. Funding: None}

11. Conflict of Interest: The authors declare no conflict of interest, financial or otherwise.

\section{References}

1. Lu H, Stratton CW, Tang Y. Outbreak of pneumonia of unknown etiology in Wuhan China: the mystery and the miracle, J Med. Virol 2020, 25678.

2. World Health Organization, WHO Director-General's Remarks at the Media Briefing on 2019-nCoV 2020. https://www.who.int/dg/speeches/ detail/who-directorgeneral-s-remarks-at-the-media-briefing-on-2019-ncovon-11- february-2020.

3. Covid-19 update. Available at: http//.google.com. Covid-19 update/Accessed $6^{\text {th }}$ April 2021.

4. Chen N, Zhou M, Dong X et al. Epidemiological and clinical characteristics of 99 cases of 2019 novel coronavirus pneumonia in Wuhan, China: a descriptive study, Lancet 2020. https://doi.org/10.1016/S01406736(20)30211-7.

5. Wang D, Hu B, Hu C et al. Clinical characteristics of 138 hospitalized patients with 2019 novel coronavirusinfected pneumonia in wuhan, China, J Am. Med. Assoc 2020. https://doi.org/10.1001/jama.2020.1585.

6. Al Najjar N, Attar L, Farahat $\mathrm{F}$ et al. Psychobehavioural responses to the 2014 Middle East respiratory syndrome-novel corona virus (MERS CoV) among adults in two shopping malls in Jeddah, western Saudi Arabia. Eastern Mediterranean Health Journal 2016;22(11):817-823.

7. Li J, Li JJ, Xie X et al. Game consumption and the 2019 novel coronavirus. The Lancet Infectious Diseases 2020;20(3):275-76. https://doi.org/10.1016/S14733099(20)30063-3

8. Centers for Disease Control and Prevention. https://www.cdc.gov/coronavirus/2019ccov/types.html (Accessed 5 March 2020)

9. Richman DD, Whitley RJ, Hayden FG. Clinical Virology, 4th ed. Washington: ASM Press 2016.

10. Chan-Yeung $\mathrm{M}, \mathrm{Xu}$ RH. SARS: epidemiology. Respirology 2003;8:S9-14.

11. Middle East Respiratory Syndrome Coronavirus. Available at: https://www.who.int/emergencies/merscov/en/. Accessed 16 Feb 2020.

12. Centers for Disease Control and Prevention, 2019 Novel Coronavirus 2020. https://www.cdc.gov/coronavirus/2019ncov/about/transmission.html.

13. Rothe C, Schunk M, Sothmann P et al. Transmission of 2019-nCoV infection from an asymptomatic contact in Germany, N. Engl. J Med. 2020. NEJMc2001468. Epub ahead of print.

14. Sahin AR, Erdogan A, Agaoglu PM et al. Novel coronavirus (COVID-19) outbreak: a review of the current literature. EJMO 2020;4(1):1-7.

15. Hui DS, Azhar EI, Madani TA et al. The continuing 2019-nCoV epidemic threat of novel coronaviruses to global health-the latest 2019 novel coronavirus outbreak in Wuhan, China. Int $\mathbf{J}$ Infect Dis 2020;91:264-6.

16. Zou L, Ruan F, Huang M et al. SARS-CoV-2 viral load in upper respiratory specimens of infected patients. N $\begin{array}{llll}\text { Engl } & \mathrm{J} & \text { Med }\end{array}$ https://doi.org/10.1056/NEJMc2001737.

17. Kampf G, Todt D, Pfaender S, Steinmann E. Persistence of coronaviruses on inanimate surfaces and its inactivation with biocidal agents. J Hosp Infect 2020, P2. S0195-6701(20)30046-3.

18. World Health Organization. Situation reports. Available at: https:// www.who.int/emergencies/diseases/novelcoronavirus-2019/ situation-reports/. Accessed 22 Feb 2020.

19. Chen H, Guo J, Wang C et al. Clinical characteristics and intrauterine vertical transmission potential of COVID-19 infection in nine pregnant women: a retrospective review of medical records. Lancet 2020. https://doi.org/10.1016/S0140-6736(20)30360-3.

20. Cheng ZJ, Shan J. Novel coronavirus: where we are and what we know. Infection 2020:1-9. https://doi.org/10.1007/s15010-020- 01401-y.

21. Chu H, Zhou J, Wong BH et al. Productive replication of Middle East respiratory syndrome corona virus in 
monocyte-derived dendritic cells modulates innate immune response. Virology 2014;454:197-205.

22. Lambeir AM, Durinx C, Scharpe S et al. Dipeptidylpeptidase IV from bench to bedside: an update on structural properties, functions, and clinical aspects of the enzyme DPP IV. Critical Reviews in Clinical Laboratory Sciences 2003;40(3):209-94.

23. Xu XW, Wu XX, Jiang XG et al. Clinical findings in a group of patients infected with the 2019 novel coronavirus (SARS-Cov-2) outside of Wuhan, China: retrospective case series. BMJ 2020;368: m606.

24. Chen F, Liu ZS, Zhang FR et al. First case of severe childhood novel coronavirus pneumonia in China. Zhonghua Er Ke ZaZhi 2020;58:E005.

25. Zeng LK, Tao XW, Yuan WH, Wang J, Liu X, Liu ZS. First case of neonate infected with novel coronavirus pneumonia in China. Zhonghua $\mathrm{Er} \mathrm{Ke}$ ZaZhi 2020;58:E009.

26. Rep WHC, SC. Undefined. (n.d.). Emerging new coronavirus infection in Wuhan, China: Situation in early 2020 .

27. Sookaromdee P, Wiwanitkit V. Imported Wuhan coronavirus infection: Is there any correlation with number of immigrants from endemic area and period after the first outbreak? In International Journal of Preventive Medicine. Wolters Kluwer Medknow Publications 2020;11(1).

https://doi.org/10.4103/ijpvm.IJPVM_41_20

28. Joob B, Wiwanitkit V. COVID-19 in medical personnel: observation from Thailand. In Journal of Hospital Infection. W.B. Saunders Ltd 2020;104(4):453. https://doi.org/10.1016/j.jhin.2020.02.016

29. Sriwijitalai W, Wiwanitkit V. COVID-19 in forensic medicine unit personnel: Observation from Thailand. In Journal of Forensic and Legal Medicine. Churchill Livingstone 2020;72:101964. https://doi.org/10.1016/j.jflm.2020.101964

30. Lu J, Gu J, Gu J, Li K, Xu C, Su W et al. COVID-19 Outbreak Associated with Air Conditioning in Restaurant, Guangzhou, China 2020. Emerging Infectious Diseases 2020;26(7):1628-1631. https://doi.org/10.3201/eid2607.200764

31. To KKW, Tsang OTY, Yip CCY, Chan KH, Wu TC, Chan JMC et al. Consistent Detection of 2019 Novel Coronavirus in Saliva. Clinical Infectious Diseases : An Official Publication of the Infectious Diseases Society of America 2020;71(15):841-843. https://doi.org/10.1093/cid/ciaa149

32. Chan JFW, Yuan S, Kok KH, To KKW, Chu H, Yang J et al. A familial cluster of pneumonia associated with the 2019 novel coronavirus indicating person-to-person transmission: a study of a family cluster. The Lancet 2020;395(10223):514-523. https://doi.org/10.1016/S0140-6736(20)30154-9

33. Rothe C, Schunk M, Sothmann P, Bretzel G, Froeschl G, Wallrauch C et al. Transmission of 2019-NCOV infection from an asymptomatic contact in Germany. In New England Journal of Medicine. Massachussetts Medical Society 2020;382(10):970-971. https://doi.org/10.1056/NEJMc2001468.

34. Lu R, Zhao X, Li J, Niu P, Yang B, Wu $\mathrm{H}$ et al. Genomic characterisation and epidemiology of 2019 novel coronavirus: implications for virus origins and receptor binding. The Lancet 202;395(10224):565-574. https://doi.org/10.1016/S0140-6736(20)30251-8

35. Baud D, Qi X, Nielsen-Saines K, Musso D, Pomar L, Favre G. Real estimates of mortality following COVID19 infection. In The Lancet Infectious Diseases. Lancet Publishing Group 2020;20(7):773. https://doi.org/10.1016/S1473-3099(20)30195-X

36. Jiang S, Xia S, Ying T, Lu L. A novel coronavirus (2019-nCoV) causing pneumonia-associated respiratory syndrome. In Cellular and Molecular Immunology. Springer Nature 2020;17(5):554. https://doi.org/10.1038/s41423-020-0372-4

37. Features, Evaluation, and Treatment of Coronavirus (COVID-19) - PubMed. (n.d.). Retrieved 2020, from https://pubmed.ncbi.nlm.nih.gov/32150360/

38. Ong SWX, Tan YK, Chia PY, Lee TH, Ng OT, Wong MSY et al. Air, Surface Environmental, and Personal Protective Equipment Contamination by Severe Acute Respiratory Syndrome Coronavirus 2 (SARS-CoV-2) from a Symptomatic Patient. In JAMA - Journal of the American Medical Association. American Medical Association 2020;323(16):1610-1612. https://doi.org/10.1001/jama.2020.3227

39. Otter JA, Donskey C, Yezli S, Douthwaite S, Goldenberg SD, Weber DJ. Transmission of SARS and MERS coronaviruses and influenza virus in healthcare settings: The possible role of dry surface contamination. In Journal of Hospital Infection. W.B. Saunders Ltd 2016;92(3):235-250. https://doi.org/10.1016/j.jhin.2015.08.027

40. Xiao S, Li Y, Wong Wai T, Hui DSC. Role of fomites in SARS transmission during the largest hospital outbreak in Hong Kong. PLoS ONE 2017;12(7). https://doi.org/10.1371/journal.pone.0181558

41. Laboratory biosafety guidance related to coronavirus disease (COVID-19). (n.d.). Retrieved 2020, from https://www.who.int/publications/i/item/laboratorybiosafety-guidance-related-to-coronavirus-disease(covid-19).

42. Sagripanti JL, Hülseweh B, Grote G, Voß L, Böhling $\mathrm{K}$, Marschall HJ. Microbial inactivation for safe and rapid diagnostics of infectious samples. Applied and Environmental Microbiology 2011;77(20):7289-7295. https://doi.org/10.1128/AEM.05553-11

43. Blow JA, Dohm DJ, Negley DL, Mores CN. Virus inactivation by nucleic acid extraction reagents. Journal of Virological Methods 2004;119(2):195-198. https://doi.org/10.1016/j.jviromet.2004.03.015

44. Ngo KA, Jones SA, Church TM, Fuschino ME, George $\mathrm{K}$, st. Lamson DM et al. Unreliable Inactivation of Viruses by Commonly Used Lysis Buffers. Applied Biosafety 2017;22(2):56-59. https://doi.org/10.1177/1535676017703383

45. Smither SJ, Weller SA, Phelps A, Eastaugh L, Ngugi S, O'Brien LM et al. Buffer AVL alone does not inactivate ebola virus in a representative clinical sample type. Journal of Clinical Microbiology 2015;53(10):3148-3154. https://doi.org/10.1128/JCM.01449-15

46. Darnell MER, Subbarao K, Feinstone SM, Taylor DR. Inactivation of the coronavirus that induces severe acute respiratory syndrome, SARS-CoV. Journal of Virological Methods 2004;121(1):85-91. https://doi.org/10.1016/j.jviromet.2004.06.006 
47. Leclercq I, Batéjat C, Burguière AM, Manuguerra JC. Heat inactivation of the Middle East respiratory syndrome coronavirus. Influenza and Other Respiratory Viruses 2014;8(5):585-586. https://doi.org/10.1111/irv.12261

48. Pan Y, Zhang D, Yang P, Poon LLM, Wang Q. Viral load of SARS-CoV-2 in clinical samples. In The Lancet Infectious Diseases. Lancet Publishing Group 2020;20(4):411-412. https://doi.org/10.1016/S14733099(20)30113-4.

49. Meyer B, Drosten C, Müller MA. Serological assays for emerging coronaviruses: Challenges and pitfalls. Virus Research 2014;194:175-183. https://doi.org/10.1016/j.virusres.2014.03.018

50. Pastorino B, Touret F, Gilles M, de Lamballerie X, Charrel R. Evaluation of heating and chemical protocols for inactivating SARS-CoV-2. BioRxiv, 2020.04.11.036855. https://doi.org/10.1101/2020.04.11.036855

51. Chang L, Yan Y, Wang L. Coronavirus Disease 2019: Coronaviruses and Blood Safety. In Transfusion Medicine Reviews. W.B. Saunders 2020;34(2):75-80. https://doi.org/10.1016/j.tmrv.2020.02.003

52. Haddock E, Feldmann F, Feldmann H. Effective chemical inactivation of Ebola virus. Emerging Infectious Diseases 2016;22(7):1292-1294. https://doi.org/10.3201/eid2207.160233

53. Wood BA, Mioulet V, Henry E, Gray A, Azhar M, Thapa B et al. Inactivation of foot-and-mouth disease virus A/IRN/8/2015 with commercially available lysis buffers. Journal of Virological Methods 2020;278:113835.

https://doi.org/10.1016/j.jviromet.2020.113835

54. Van Doremalen N, Bushmaker T, Morris DH, Holbrook MG, Gamble A, Williamson BN et al. Aerosol and surface stability of SARS-CoV-2 as compared with SARS-CoV-1. In New England Journal of Medicine. Massachussetts Medical Society 2020;382(16):15641567. https://doi.org/10.1056/NEJMc2004973

55. Roehrig JT, Hombach J, Barrett ADT. Guidelines for plaque-reduction neutralization testing of human antibodies to dengue viruses. Viral Immunology 2008;21(2):123-132.

https://doi.org/10.1089/vim.2008.0007

56. Transcript for the CDC Telebriefing Update on COVID-19 | CDC Online Newsroom | CDC. (n.d.). Retrieved 2020, from

https://www.cdc.gov/media/releases/2020/t0225-cdctelebriefing-covid-19.html

57. Cohly HHP, Panja A. Immunological Findings in Autism. International Review of Neurobiology 2005;71(05): 317-341. https://doi.org/10.1016/S00747742(05)71013-8

58. Su S, Wong G, Shi W, Liu J, Lai ACK, Zhou J et al. Epidemiology, Genetic Recombination, and Pathogenesis of Coronaviruses. In Trends in Microbiology. Elsevier Ltd 2016;24(6):490-502. https://doi.org/10.1016/j.tim.2016.03.003

59. Killerby ME, Biggs HM, Haynes A, Dahl RM, Mustaquim D, Gerber SI et al. Human coronavirus circulation in the United States 2014-2017. Journal of Clinical Virology 2018;101:52-56. https://doi.org/10.1016/j.jcv.2018.01.019

60. Neher RA, Dyrdak R, Druelle V, Hodcroft EB, Albert
J. Potential impact of seasonal forcing on a SARSCoV-2 pandemic. Swiss Medical Weekly 2020;150(1112):w20224.

https://doi.org/10.4414/smw.2020.20224.

61. Callow KA, Parry HF, Sergeant M, Tyrrell DAJ. The time course of the immune response to experimental coronavirus infection of man. Epidemiology and Infection 1990;105(2):435-446.

https://doi.org/10.1017/S0950268800048019

62. Ferretti L, Wymant C, Kendall M, Zhao L, Nurtay A, Abeler-Dörner L, Parker M et al. Quantifying SARSCoV-2 transmission suggests epidemic control with digital contact tracing. Science 2020;368:6491. https://doi.org/10.1126/science.abb6936

63. Hauser A, Counotte M, Margossian C, Konstantinoudis G, Low N, Althaus C et al. Estimation of SARS-CoV-2 mortality during the early stages of an epidemic: a modeling study in Hubei, China, and six regions in Europe. MedRxiv 2020. 03.04.20031104. https://doi.org/10.1101/2020.03.04.20031104

64. Anderson RM, Heesterbeek H, Klinkenberg D, Hollingsworth TD. How will country-based mitigation measures influence the course of the COVID-19 epidemic? In The Lancet 2020;395(10228):931-934. Lancet Publishing Group. https://doi.org/10.1016/S0140-6736(20)30567-5

65. Chen C, Zhao B. Makeshift hospitals for COVID-19 patients: where health-care workers and patients need sufficient ventilation for more protection. In Journal of Hospital Infection 2020;105(1):98-99. W.B. Saunders Ltd 2020. https://doi.org/10.1016/j.jhin.2020.03.008

66. Coronavirus: How can China build a hospital so quickly? BBC News. (n.d.) Retrieved 2020. From https://www.bbc.com/news/world-asia-china-51245156

67. Coronavirus: Thousands of extra hospital beds and staff - BBC News. (n.d.). Retrieved 2020 from https://www.bbc.com/news/uk-51989183

68. Pentagon says it will give 5 million respirators, 2, 000 ventilators to Health and Human Services for virus response. (n.d.). Retrieved 2020 from https://apnews.com/79e98812b5b1592a134803b00c8d8 $8 \mathrm{~b} 0$

69. Kissler SM, Tedijanto C, Goldstein E, Grad YH, Lipsitch M. Projecting the transmission dynamics of SARS-CoV-2 through the postpandemic period. Science 2020;368(6493):860-868. https://doi.org/10.1126/science.abb5793

70. FluView Interactive | CDC. (n.d). Retrieved 2020, from https://www.cdc.gov/flu/weekly/fluviewinteractive.htm

71. Beest DET, Van Boven M, Hooiveld M, Van Den Dool C, Wallinga J. Driving factors of influenza transmission in the Netherlands. American Journal of Epidemiology 2013;178(9):1469-1477. https://doi.org/10.1093/aje/kwt132

72. Ferguson NM, Laydon D, Nedjati-Gilani G, Imai N, Ainslie K, Baguelin M et al. of non-pharmaceutical interventions (NPIs) to reduce COVID-19 mortality and healthcare demand. https://doi.org/10.25561/77482

73. Lauer SA, Grantz KH, Bi Q, Jones FK, Zheng Q, Meredith $\mathrm{HR}$ et al. The incubation period of coronavirus disease 2019 (CoVID-19) from publicly reported confirmed cases: Estimation and application. Annals of Internal Medicine 2020;172(9):577-582. https://doi.org/10.7326/M20-0504 
74. Linton N, Kobayashi T, Yang Y, Hayashi K, Akhmetzhanov A, Jung S et al. Incubation Period and Other Epidemiological Characteristics of 2019 Novel Coronavirus Infections with Right Truncation: A Statistical Analysis of Publicly Available Case Data. Journal of Clinical Medicine 2020;9(2):538. https://doi.org/10.3390/jcm9020538

75. Read J, Bridgen JR, Cummings DA, Ho A, Jewell C. Novel coronavirus 2019-nCoV: early estimation of epidemiological parameters and epidemic predictions. MedRxiv 2020. 2020.01.23.20018549. https://doi.org/10.1101/2020.01.23.20018549

76. Shaman J, Galanti M. Direct Measurement of Rates of Asymptomatic Infection and Clinical Care-Seeking for Seasonal Coronavirus. MedRxiv 2020. 2020.01.30.20019612. https://doi.org/10.1101/2020.01.30.20019612

77. Handel A, Longini IM, Antia R. What is the best control strategy for multiple infectious disease outbreaks? Proceedings of the Royal Society B: Biological Sciences 2007;274(1611):833-837. https://doi.org/10.1098/rspb.2006.0015

78. Peak C, Kahn R, Grad Y, Childs L, Li R, Lipsitch M et al. Modeling the Comparative Impact of Individual Quarantine vs. Active Monitoring of Contacts for the Mitigation of COVID-19. MedRxiv: The Preprint Server for Health Sciences 2020. 2020.03.05.20031088. https://doi.org/10.1101/2020.03.05.20031088

79. Coronavirus: Thousands of extra hospital beds and staff - BBC News. (n.d.). Retrieved 2020, from https://www.bbc.com/news/uk-51989183

80. Hatchett RJ, Mecher CE, Lipsitch M. Public health interventions and epidemic intensity during the 1918 influenza pandemic. Proceedings of the National Academy of Sciences of the United States of America 2007;104(18):7582-7587. https://doi.org/10.1073/pnas.0610941104

81. Huang KE, Lipsitch M, Shaman J, Goldstein E. The US 2009 A (H1N1) Influenza Epidemic. Epidemiology 2014;25(2):203-206. https://doi.org/10.1097/EDE.0000000000000055

82. Goldstein E, Cobey S, Takahashi S, Miller JC, Lipsitch M. Predicting the Epidemic Sizes of Influenza A/H1N1, A/H3N2, and B: A Statistical Method. PLoS Medicine 2011;8(7):e1001051. https://doi.org/10.1371/journal.pmed.1001051

83. 2017 Report - State of the Tropics - James Cook University. (n.d.). Retrieved, 2020 from https://www.jcu.edu.au/state-of-thetropics/publications/2017

84. Li R, Pei S, Chen B, Song Y, Zhang T, Yang W et al. Substantial undocumented infection facilitates the rapid dissemination of novel coronavirus (SARS-CoV-2). Science 2020;368(6490):489-493. https://doi.org/10.1126/science.abb3221

85. Fu Y, Cheng Y, Wu Y. Understanding SARS-CoV-2Mediated Inflammatory Responses: From Mechanisms to Potential Therapeutic Tools. In Virologica Sinica. Science Press 2020;35(3):266-271. https://doi.org/10.1007/s12250-020-00207-4

86. Tetro JA. Is COVID-19 receiving ADE from other coronaviruses? Microbes and Infection 2020;22 (2):7273. https://doi.org/10.1016/j.micinf.2020.02.006

87. Bi Q, Wu Y, Mei S, Ye C, Zou X, Zhang Z et al.
Epidemiology and Transmission of COVID-19 in Shenzhen China: Analysis of 391 cases and 1, 286 of their close contacts. MedRxiv 2020. 2020.03.03.20028423.

https://doi.org/10.1101/2020.03.03.20028423

88. Kraemer MUG, Yang CH, Gutierrez B, Wu CH, Klein $\mathrm{B}$, Pigott DM et al. The effect of human mobility and control measures on the COVID-19 epidemic in China. Science, 2020;368(6490):493-497. https://doi.org/10.1126/science.abb4218

89. Lipsitch M, Viboud C. Influenza seasonality: Lifting the fog. In Proceedings of the National Academy of Sciences of the United States of America. National Academy of Sciences 2009;106(10):3645-3646. https://doi.org/10.1073/pnas.0900933106

90. Sahu KK, Kumar R. Preventive and treatment strategies of COVID-19: From community to clinical trials. J Family Med Prim Care 2020;9:2149-57.

91. Grein J, Ohmagari N, Shin D, Diaz G, Asperges E, Castagna A et al. Compassionate use of remdesivir for patients with severe Covid-19. N Engl J Med 2020. doi: 10.1056/NEJMoa2007016.

92. Dong $\mathrm{L}, \mathrm{Hu} \mathrm{S}$, Gao J. Discovering drugs to treat coronavirus disease 2019 (COVID-19). Drug DiscovTher 2020;14(1):58-60.

93. Shah S, Das S, Jain A, Misra DP, Negi VS. A systematic review of the prophylactic role of chloroquine and hydroxychloroquine in coronavirus disease-19 (COVID-19). Int J Rheum Dis 2020. doi: 10.1111/1756-185X.13842.

94. Ferrara G, Zumla A, Maeurer M. Intravenous immunoglobulin (IVIg) for refractory and difficult-totreat infections. Am J Med 2012;125:1036.e1-8.

95. Cao W, Liu X, Bai T, Fan H, Hong K, Song H et al. High-dose intravenous immunoglobulin as a therapeutic option for deteriorating patients with coronavirus disease 2019. Open Forum Infect Dis 2020;7:102.

96. Shen C, Wang Z, Zhao F, Yang Y, Li J, Yuan J et al. Treatment of 5 critically ill patients with COVID-19 with convalescent plasma. JAMA 2020. doi: 10.1001/jama. 2020.4783.

97. Zhang C, Wu Z, Li JW, Zhao H, Wang GQ. The cytokine release syndrome (CRS) of severe COVID-19 and Interleukin-6 receptor (IL-6R) antagonist Tocilizumab may be the key to reduce the mortality. Int J Antimicrob Agents 2020, 105954 doi: 10.1016/j.ijantimicag. 2020.105954.

98. Leng Z, Zhu R, Hou W, Feng Y, Yang Y, Han et al. Transplantation of ACE2 (-) mesenchymal stem cells improves the outcome of patients with COVID-19 pneumonia. Aging Dis 2020;11:216-28. 